\title{
EL DIFERENCIAL CAMBIARIO EN LA FRONTERA NORTE DE SANTANDER, COLOMBIA Y VENEZUELA. ¿LA ECONOMÍA O LA POLÍTICA?
}

\author{
THE EXCHANGE RATE DIFFERENTIAL ON THE BORDER NORTE DE \\ SANTANDER, COLOMBIA AND VENEZUELA. THE ECONOMICS OR POLITICS? \\ O DIFERENCIAL DE TAXA DE CÂMBIO NA FRONTEIRA NORTE DE \\ SANTANDER, COLÔMBIA E VENEZUELA. A ECONOMIA OU A POLÍTICA?
}

\author{
Por: PABÓN LEÓN - Jhon Antuny, BASTOS OSORIO - Liliana Marcela, \\ MOGROVEJO ANDRADE - Johanna Milena
}

\begin{abstract}
Magister en Gerencia de empresas Universidad Nacional Experimental del Táchira (San Cristóbal, Venezuela), Profesor Tiempo Completo Departamento de Ciencias Empresariales, Universidad Francisco de Paula Santander, Cúcuta. jhonantuny@ufps.edu.co

Magister en Gerencia de empresas Universidad Nacional Experimental del Táchira (San Cristóbal, Venezuela), Profesor Tiempo Completo Departamento de Estudios internacionales y de fronteras, Universidad Francisco de Paula Santander, Cúcuta. lilianamarcelabo@ufps.edu.co

Candidato a Doctor en estudios políticos de la Universidad Externado, Magister en Gerencia de empresas Universidad Nacional Experimental del Táchira (San Cristóbal, Venezuela), Profesor Tiempo Completo Departamento de Estudios internacionales y de fronteras, Universidad Francisco de Paula Santander, Cúcuta. johannamogrovejo@ufps.edu.co
\end{abstract}

\section{RESUMEN}

Se analiza el diferencial cambiario en la frontera Norte de Santander Colombia y Venezuela desde el punto de vista de ambas naciones argumentado en una reflexión teórica. La llamada "frontera más viva de Latinoamérica" presenta alta intensidad de comercio transfronterizo con un alto arraigo histórico que hace interdependientes ambas regiones. Su estudio es importante, la visión de la economía venezolana ha producido desajustes que se han trasladado a una región donde existe una economía de mercado que se ha afectado por el diferencial cambiario propiciando el contrabando y otras modalidades nuevas como el "bachaqueo", donde comercian con dos o tres productos y los maleteros que transportan a través del río. Allí no existe consenso en cuanto a las causas del diferencial cambiario, para unos es consecuencia del mercado y de los desequilibrios originados por las políticas del gobierno venezolano, para otros es consecuencia de la especulación y de las mafias de la frontera. Ante esta realidad con visiones antagónicas, concuerda la proposición de la asimetría complementaria de los estados colindantes, se considera que priva el matiz político venezolano sobre la economía y existe un caos organizado en el 
manejo del diferencial cambiario beneficiándose los diferentes actores aunque se exprese lo contrario.

Palabras clave: diferencial cambiario, región fronteriza, políticas cambiarias, economía oculta.

JEL: E5, F1, F2

\section{ABSTRACT}

The exchange rate differential on the border North of Santander Colombia and Venezuela is analyzed from the point of view of both Nations argued in a theoretical reflection. So-called 'border more lively Latin America' presents high-intensity of cross-border trade with a high historical roots making interdependent both regions. Their study is important, the vision of the Venezuelan economy has produced maladjustments which have moved to a region where there is a market economy that has affected by the differential Exchange to smuggling and other new modalities such as 'bachaqueo', where trade with two or three products and the porters carrying across the river. There consensus about the causes of exchange rate differential, for a few is there is no consequence of the market and of the imbalances caused by the policies of the Venezuelan Government, for others is the result of speculation and the mafia of the border. Before this reality with antagonistic visions, agrees the proposition of the additional asymmetry of adjoining States, is considered that it deprives the Venezuelan political nuance on the economy and there is a chaos organized in the management of the differential exchange benefiting stakeholders but be expressed otherwise.

Keywords: exchange rate differential, border region, exchange rate policies, economy hides.

JEL: E5, F1, F2

\section{RESUMO}

O diferencial de taxa de câmbio na fronteira norte de Santander Colômbia e Venezuela é analisado do ponto de vista de ambas as Nações argumentado em uma reflexão teórica. So-called 'fronteiriços mais animada da América Latina' apresenta alta intensidade do comércio transfronteiriço com uma alta raízes históricas tornando interdependentes de ambas as regiões. Seu estudo é importante, a visão da economia venezuelana produziu antipoluição que mudou-se para uma região onde há uma economia de mercado que tenha afetado pela troca diferencial de contrabando e outras novas modalidades tais como 'bachaqueo', onde o comércio com dois ou três produtos e cruza o rio com os porteiros. Há consenso sobre as causas da taxa de câmbio, diferencial, para alguns é que não há nenhuma consequência do mercado e dos desequilíbrios causados pelas políticas do governo venezuelano, para outros é o resultado de especulação e a máfia da fronteira. Antes desta realidade com visões antagônicas, concorda com a proposta de assimetria adicional do adjacente Estados, é considerada que priva a nuance política venezuelana sobre a economia e há um caos organizado na gestão do diferencial trocar beneficiando os interessados mas ser expressa de outra forma.

Palavras-chave: taxa de câmbio diferencial, região fronteiriça, condições de taxa de câmbio, couros de economia.

JEL: E5, F1, F2 


\section{INTRODUCCIÓN}

El presente artículo de reflexión deriva de un proyecto de investigación titulado "Impacto económico de las coyunturas políticas Colombo-Venezolanas en la zona de frontera”. Argumentado en una reflexión teórica se estudia su comportamiento con base en la proposición de la asimetría complementaria de los estados colindantes. Tiene como propósito examinar el diferencial cambiario en la frontera Norte de Santander Colombia y Venezuela desde el punto de vista de ambas naciones en el marco de las políticas comerciales y económicas de los dos países en razón que el departamento Norte de Santander es uno de los más afectados por la caída de la actividad debido al fuerte lazo histórico, social y comercial con el estado Táchira en Venezuela.

A esta región fronteriza se le ha llamado "la frontera más viva de Latinoamérica". En esta zona se presenta alta intensidad del comercio transfronterizo con un alto arraigo histórico que las hacen interdependientes. El artículo busca explicar las conductas económicas que identifican a ambos lados de la frontera al consumidor fronterizo. El comportamiento de este comercio depende del tipo de cambio, la inflación y por las restricciones para cruzar hacia uno u otro país. Analizar lo que sucede en la zona de la frontera es importante dado el impacto económico y social que repercute en la zona de influencia de las ciudades fronterizas.

En los últimos años Colombia, donde la moneda de curso legal es el Peso Colombiano (COP), ha mostrado fortaleza frente a la moneda de los socios comerciales, especialmente en el caso de la frontera Colombia-Venezuela país en donde la moneda oficial es el Bolívar (VEB). Durante muchos años Venezuela ha sido uno de los destinos prioritarios en el comercio internacional de Colombia enfrentando periodos de auge y también de crisis influenciadas mayormente por el tinte político. Esta tensión llegó a su máxima expresión a partir de agosto de 2009 cuando se hizo público el acuerdo militar de Colombia con Estados Unidos estando en la presidencia de Colombia Alvaro Uribe Vélez y en la de Venezuela Hugo Chávez Frías.

En relación a estas coyunturas debe señalarse que cada vez es más difícil el intercambio comercial con Venezuela planteándose un escenario de incertidumbre respecto al mercado venezolano. Son muchos los factores que influyen entre ellos mencionamos las barreras impuestas por el gobierno venezolano al intercambio comercial, control de cambio de divisas en Venezuela lo cual dificulta el cumplimiento de los compromisos y pagos correspondientes afectando la confianza en los exportadores junto a decisiones políticas compulsivas desde el lado venezolano. Es así como a partir del lunes 11 de agosto de 2014 el Gobierno venezolano tomó la decisión de cierres temporales de los puentes internacionales Simón Bolívar y Francisco de Paula Santander. La acción se deriva del desabastecimiento que genera la extracción de mercancías de consumo masivo y gasolina hacia la frontera. Asimismo existe un diferencial cambiario en frontera que hace muy atractiva la comercialización de productos en el mercado de la ciudad de Cúcuta y su Área Metropolitana. Se estima que el $40 \%$ de productos venezolanos se esfuman en la porosa línea fronteriza y se calcula un contrabando de USD 3.600 millones anuales hacia Colombia. 
Mientras la economía Venezolana se desabastece, la economía fronteriza se torna un mercado informal y evasivo fiscalmente que perfora los recursos de los entes territoriales e incide de manera directa en la economía formal de la ciudad. A los productores de Colombia les significa una competencia desleal que los arruina y aumenta el desempleo en la frontera, de hecho según información recabada de la Policía Fiscal Aduanera, las incautaciones a octubre 2014 llegan a los \$12.378 millones, incrementándose en un $46 \%$ con relación al mismo periodo de 2013 , que llegaron a \$ 9.112 millones.

En el presente trabajo se conceptualiza como Tipo de Cambio el precio de una moneda expresado en otra y cuando está en manos extranjeras se le llama divisa. En referencia a las Políticas Económicas se considera así a las herramientas de intervención del Estado en la economía para alcanzar unos objetivos. Por su parte Política Monetaria es el conjunto de medidas que toma la autoridad monetaria de cada país con el objetivo de lograr la estabilidad de los precios a través de variaciones en la cantidad de dinero en circulación. Como Política Exterior la intervención que realizan los gobiernos para regular las transacciones con otros países. Algunos ejemplos de política económica son la fijación del tipo de cambio de la moneda respecto a las monedas de otros países, el fomento de las exportaciones o las limitaciones a las importaciones.

El trabajo discurre analizando las relaciones fronterizas, la política cambiaria implementada en Colombia y en Venezuela y las consecuencias del diferencial cambiario en la zona fronteriza. Igualmente se buscó información que permita evaluar las posiciones asumidas por voceros de ambos países respecto a las consecuencias devenidas en la región fronteriza por el diferencial cambiario.

Como objetivo del estudio se plantea analizar el diferencial cambiario en la frontera desde la visión de ambos países en el marco de las políticas comerciales y económicas de los dos países. La hipótesis que se estudia es que el diferencial cambiario en la frontera Norte de Santander Colombia y Venezuela ha devenido en un caos organizado; dada la naturaleza del estudio se toma como eje temático las Asimetrías de Políticas Públicas de Acceso al Mercado. Para ello se efectuó una revisión bibliográfica con el fin de conocer datos socio económicos en el departamento Norte de Santander Colombia y el estado Táchira en Venezuela, se indagó sobre el comportamiento histórico de la tasa de cambio en la zona fronteriza y se analizó la política cambiaria entre Colombia y Venezuela así como las posiciones asumidas por voceros de ambos países.

\section{RELACIONES EN LAS FRONTERAS}

Se encontró información de diversos autores, los trabajos escogidos se clasificaron de acuerdo al eje temático desplegado en Comercio fronterizo citamos a: Rodríguez (2014) y Sánchez (2014). Sobre Política Monetaria a: García (2010) y Martínez (2008). En cuanto a Política Exterior Ramírez (2011) y relacionado con Política Fiscal: López (2011).

$\mathrm{Al}$ analizar el comportamiento del consumidor en ciudades fronterizas se encontró que este presenta un patrón común dado por los beneficios que pueda obtener en 
el intercambio comercial. Las relaciones que se establecen en las zonas fronterizas están determinadas por las asimetrías en las economías de los países colindantes y esos factores están bastante diferenciados en la frontera objeto del presente estudio. La anterior afirmación se sustenta en la evidencia empírica recopilada, donde se ha detectado que mientras más barreras han colocado en Venezuela a la relación fronteriza ha traído como consecuencia el aumento de prácticas ilegales algunas nuevas como el "bachaqueo" y el incremento de los "maleteros". Como consecuencia se extendió el contrabando de extracción desde Venezuela aprovechando los diferenciales de precio lo cual alimentó la corrupción en algunos funcionarios civiles y militares de ambos países destacados en la frontera apoyando esas prácticas ilegales. Por ejemplo mientras Venezuela es el país con la gasolina más barata del mundo, Colombia es el tercer país con la gasolina más cara.

\subsection{Las asimetrías en las fronteras}

En (SELA, 2011: 3) se indica que las asimetrías son percibidas como una traba para el desarrollo dinámico y sustentable de los países de menor desarrollo o de menor tamaño y también entre las subregiones. Se puede considerar en este caso que entre el departamento Norte de Santander y el estado Táchira en Venezuela existe una subregión de condiciones muy particulares dado el fuerte intercambio comercial y las históricas raíces sociales y culturales que existen entre ellos. Por ello las divergencias y trabas impactan fuertemente en todos los ámbitos especialmente en el económico, esa situación se refleja en que dado que la carencia de productos e insumos en Venezuela es suplida por el mercado colombiano. Así mismo la diferencia de precios ha propiciado un flujo comercial amparado en la economía oculta o subterránea.

Ahora bien, esta situación está determinada por las estrategias de los gobiernos centrales donde se manifiestan las asimetrías en las estrategias de ambos países, mientras Colombia se enfoca en una relación cercana con Estados Unidos y por ello ha puesto énfasis en consolidar el Acuerdo de Libre Comercio, Venezuela ha mirado hacia el Sur buscando establecer alianzas con Mercosur marcando distancias aparentes con los Estados Unidos dado que la renta petrolera venezolana está fuertemente ligada a las negociaciones con ese país y las controversias mediáticas no se reflejan en la relación comercial.

Cabe destacar que las asimetrías son estructurales; comerciales, tanto cuantitativas como cualitativas; de políticas públicas, principalmente en acceso y en incentivos; e institucionales. La aparente diferencia entre seguridad fronteriza y desarrollo económico fronterizo constituye las dos caras de una misma moneda, una imagen común en todas las zonas de frontera de América Latina y el Caribe basada en la falta de igualdad de oportunidades y en las asimetrías tanto a nivel nacional como intrarregional que limitan las estrategias de desarrollo personales y societales, es decir, la imposibilidad de generar una transformación productiva con equidad tal como se presenta en CEPAL 2010 (citado en SELA, 2013: 2).

Las asimetrías se clasifican en estructurales, comerciales, de políticas públicas e institucionales. (SELA, 2011: 25). Las asimetrías de políticas públicas se subdividen en: 
a) de acceso al mercado: Se trata de las limitaciones permanentes o transitorias, previsibles o imprevisibles, que algunos (s) de los miembros aplica (n), por su sola voluntad, en perjuicio de los otros socios, alegando razones de fuerza mayor. Generalmente se recurre a licencias para importación, retenciones de mercaderías en frontera sin causa justificable, barreras no arancelarias, modificaciones en los impuestos indirectos, etc.

b) de incentivos: Provienen de las distorsiones que genera la ausencia de incentivos comunes o regionales en los procesos de integración, así como de la dificultad que enfrentan los países pequeños o de menor desarrollo para aplicar políticas de incentivos a las inversiones y exportaciones similares a las aplicadas por los países más desarrollados.

Dada la naturaleza del estudio se toma como eje temático las Asimetrías de Políticas Públicas de Acceso al Mercado. Visto de esta forma este trabajo busca orientar el análisis hacia el ámbito comercial en virtud de las coyunturas económicas que se han presentado en la región fronteriza como respuesta a los conflictos políticos.

En efecto a partir del año 2009 empieza a presentarse una reducción del comercio binacional debido a los conflictos diplomáticos, aunado al menor ritmo de crecimiento de Colombia y Venezuela por efectos de la crisis económica mundial. Evidentemente la ciudad de Cúcuta como referente del departamento Norte de Santander en el año 2013 presentó una situación económica crítica la que no fue imputable solo a la devaluación del bolívar, también influyó el diferencial cambiario más aún cuando Cúcuta es una ciudad donde la economía se sustenta en el comercio relacionado más con Venezuela que hacia el interior del país. Ante este panorama se hace inaplazable reenfocar la estrategia de desarrollo en el departamento Norte de Santander en aras de romper la tradicional dependencia del mercado venezolano. Para ello se requiere la concurrencia de los diferentes actores que hacen vida en la región. El departamento Norte de Santander ha sido observado y tratado desde el gobierno central bajo el criterio de Estado-Nación y no desde el punto de vista de región fronteriza que tiene características propias y una dinámica muy diferente a la que se percibe desde los círculos de poder.

\subsection{Comercio Internacional}

En los primeros mercados, el sistema fue de "canje” o "trueque”, posteriormente se comenzaron a adoptar como medidas de canje metales preciosos luego a finales de la Edad Media se dio la aparición y circulación del papel moneda y se adoptó su uso como medida corriente por parte de los gobiernos. La moneda moderna típicamente toma la forma de dinero fiduciario, el cual se refiere a la moneda que no está respaldada por reservas de oro u otra mercancía preciosa, diferente a la moneda representativa.

Cabe destacar según Martínez (2001) que la flexibilidad del sistema actual y la diversidad de situaciones concretas en que se encuentran muchos países, algunos muy endeudados, otros escasos de reservas, otros con fuerte dependencia tecnológica o de materias primas, hace que se multipliquen los sistemas de pagos internacionales recurriendo incluso con cierta frecuencia a formas que, como el 
trueque, parecían haber quedado obsoletas. Agrega Martínez (2001) que algunos países han decidido fijar estrechamente el valor de su moneda al de otra. En otras ocasiones aparecen tipos de cambio fijos y múltiples, un tipo de cambio para el pago de deudas, otro para inversiones, otro para importaciones. Algunos grupos de países han llegado a acuerdos mutuos sobre sistemas cambiarios particulares, el más avanzado de los cuales es el Sistema Monetario Europeo, se percibe entonces que la función principal que desempeña el dinero en el comercio mundial es la de medio de pago.

Pero ¿qué consecuencias económicas derivan de la intervención de los gobiernos? Ante esta interrogante existe evidencia empírica que relaciona una elevada tasa de inflación con un menor crecimiento económico. Igualmente se ha encontrado que altos déficits fiscales referenciados con el Producto Interno Bruto afectan el crecimiento, cabe considerar entonces que las políticas cambiarias y fijación del tipo de cambio al influir en el diferencial cambiario afectan el desenvolvimiento de la economía del país que los aplica.

Se plantea entonces el problema de las fronteras como testigos permanentes del intercambio entre ellas y de las distorsiones que se presentan a ambos lados con la finalidad de burlar o evadir los controles establecidos. De allí pues que esta serie de movimientos han llevado a criminalizar actividades que perjudican la recaudación de los países fronterizos así como el control de la producción y distribución de recursos afectando la industria y comercio formalmente establecido. Desde el punto de vista social la transmisión del efecto del valor agregado a la economía se diluye afectando a las clases más vulnerables de la sociedad dado que los impuestos que en teoría serían destinados a salud y educación no llegan al Estado.

Para ilustrar esto citamos algunos casos en nuestro continente que hacen referencia a la situación planteada en el presente análisis. Por ejemplo en la frontera Estados Unidos-México el tipo de cambio peso-dólar es una de las variables que determinan el comportamiento de las compras al menudeo, en las ciudades americanas a lo largo de la frontera con México. Otra variable es la inflación y en México tuvo su máxima expresión en 1987 cuando se incrementó hasta 187\%.

Similar es la situación en la frontera Bolivia-Argentina, tal como se explicó en el artículo "Por la devaluación del peso, los bolivianos cruzan a comprar"1, en el 7 mes de octubre de 2014: miles de bolivianos cruzan todos los días la frontera internacional en la localidad salteña de Salvador Mazza para comprar bienes de consumo a precios más económicos que en sus ciudades de origen debido a la devaluación local y vuelven a sus casas con provisiones para varias semanas. Esta situación se presenta porque según el cambio oficial, por cada peso boliviano los visitantes reciben entre 1,19 y 1,21 pesos argentinos, aunque en el mercado negro de divisas la rentabilidad puede llegar al 250 por ciento. Pero más que el tipo de cambio oficial o paralelo, las transacciones comerciales se dan directamente con la moneda del vecino país en un valor definido por los comerciantes argentinos, lo que ubica a la brecha cambiaria en 120 por ciento.

1. www.resistenciahuemul.com.ar. 
En nuestra opinión si se eliminan las nacionalidades se podría considerar que se refiere a la frontera entre Colombia y Venezuela u otra cualquiera donde exista el diferencial cambiario. De hecho cruzando la frontera, en el municipio de Bermejo, Bolivia, los comerciantes explican a viva voz los beneficios de comprar mercadería argentina. Hoy, se necesitan $\$ 2$ argentinos para comprar \$1 boliviano. El 2 a 1 permite el ingreso de grandes cantidades de alimento al territorio vecino: harina, aceites, cervezas, gaseosas, golosinas, que se consumen en las localidades como Pocitos, Yacuiba y Bermejo, entre otras. Pero también se envían a otros distritos del país vecino. "Vienen y se llevan todo: champú, dentífrico, alimentos como la harina, azúcar, el arroz. A ellos les conviene porque está barato. Uno cruza a Bermejo y está caro para nosotros, por el cambio.

Ante esta realidad, se evidencia que priva el concepto económico sobre el político tomando en consideración que los mandatarios de ambos países son aliados ideológicos. En esta zona la historia se revirtió, en los años 90 miles de argentinos cruzaban la frontera debido a que el peso era equivalente al valor de un dólar y los bienes resultaban más baratos en los comercios bolivianos mientras que ahora los tours de compras vienen desde Bolivia para adquirir todo tipo de mercaderías y la primera localidad con la que se encuentran los compradores provenientes de ciudades bolivianas como Yacuiba, San José de Pocitos o Villamontes es Salvador Mazza.

Igualmente De Santis (2013) refirió que las fronteras de las ciudades argentinas limítrofes con Bolivia, Brasil, Paraguay se colman de extranjeros que entran al país para comprar combustible, comida, artículos de higiene personal y ropa. El fenómeno se produjo por el crecimiento en el precio del dólar informal, que pasó de 6,32 a 9,05 pesos en los últimos seis meses del año 2013. La brecha cambiaria -la diferencia entre el precio oficial y paralelo del dólar- se duplicó desde noviembre pasado hasta hoy y, en consecuencia, revalorizó considerablemente el poder de compra de la moneda de los países vecinos. Del lado argentino se pueden comprar los mismos artículos que al otro lado de la frontera entre 20 y $40 \%$ más baratos. Un verdadero paraíso comercial. Veranito cambiario para los extranjeros que hacen las compras en la frontera.

Con relación a Colombia, Carrión (2011) al analizar el comercio entre Ecuador y Colombia, sostiene que en la frontera colombo-ecuatoriana, se suman las transformaciones de los dos países y el fortalecimiento de la economía de frontera, sustentada en la asimetría complementaria de los Estados colindantes. Agrega Carrión que la economía de frontera integra dos o más economías asimétricas -por ser funcionales entre sí- gracias a que: lo que es legal acá es ilegal allá, lo que existe acá no existe allá o lo que tiene precio mayor acá es menor que allá; por ello hay un flujo mercantil que genera un sistema de ilegalidades donde la economía de un lado se riega sobre la otra, a la manera de vasos comunicantes. Este es el caso del contrabando y los tráficos.

Evidentemente en la investigación de Carrión se ejemplifica la diversidad de situaciones que se pueden presentar en un mismo país en sus relaciones con los vecinos influenciadas por factores del entorno sean estos económicos, políticos o sociales. En el caso de Colombia se observan dos situaciones antagónicas con res- 
pecto a Venezuela y Ecuador donde en un caso Colombia es beneficiario mientras en el otro es afectado. Claro está que en el caso de Venezuela ese país ha impuesto políticas proteccionistas levantando barreras al intercambio comercial creando así conflictos económicos y sociales a diferencia de lo que ha ocurrido en la frontera con Ecuador. Por esto los diferentes enfoques ideológicos en la forma de gobierno entre Colombia y Venezuela han agudizado la salida del conflicto.

Dentro de este marco Samaniego (2011: 9) comenta que Ecuador fue durante la última década permanentemente deficitario en materia comercial respecto a Colombia y no se observa ninguna influencia importante del nivel del tipo de cambio real sobre la dirección del comercio. Agrega que por lo general tanto lo que importa el Ecuador de Colombia como las exportaciones hacia ese país tienen una misma tendencia pero que podría ocurrir que buena parte de la dirección del intercambio comercial entre los dos países se realice en aquellos bienes que se transan sin registros por la ausencia de control en las fronteras de ambas partes. Como consecuencia suelen aparecer noticias de prensa que alertan sobre posibles desabastecimientos como efecto de exportaciones no registradas hacia Colombia y tales transacciones no solo son realizadas por pequeños comerciantes, casi al menudeo, sino también por grandes empresarios que guardan características de informalidad. Una hipótesis para entender la inflexibilidad del comercio al tipo de cambio apuntaría a que las variaciones más importantes en exportaciones e importaciones en respuesta al nivel del tipo de cambio real ocurrirían en el comercio no registrado. Un segundo aspecto es que la balanza comercial entre ambos países favorece ampliamente a Colombia debido a que Ecuador exporta cada vez menos en volumen e importa similar cantidad en volumen. La ventaja de Ecuador es que sus productos de exportación han visto crecer los precios más que las compras que realiza el país en el vecino del norte. Eventualmente, esa mejora en la relación de precios a favor del Ecuador podría estar condicionada porque los períodos en que el tipo de cambio real ha estado depreciado han sido más frecuentes que los períodos en que ha estado apreciado, es decir, hay una ganancia en precio en un ambiente de un volumen exportado cada vez menor.

En atención a la problemática expuesta queda claro en el análisis de Samaniego (2011), como se impactan los flujos comerciales ante cambios en los factores económicos sin presencia necesariamente de factores políticos. No obstante queda la inquietud e incertidumbre sobre la implementación de una política comercial estratégica por parte de un país y las posibles reacciones de otros gobiernos.

\subsection{Política Exterior Colombia-Venezuela}

En esta perspectiva entre Colombia y Venezuela las relaciones políticas han sido determinantes particularmente en los últimos quince años. Dentro de este marco Ramírez (2011) analiza la política internacional de Colombia y Venezuela, al respecto señala que se observa una dinámica diferente de los dos países, no sólo frente a la discusión de temas relevantes como la soberanía nacional y el papel de los organismos multilaterales, sino también en lo que tiene que ver con la integración continental y la aplicación del sistema democrático de la OEA. Pero, dentro de esas estrategias que aparecen como divergentes, resalta la posición que han adoptado 
los dos países en sus relaciones con los Estados Unidos. Colombia históricamente ha utilizado una estrategia de Respice Polum (mirar al polo o mirar al norte) lo que se ha reflejado en el impulso del Tratado de Libre Comercio (TLC) con los Estados Unidos, por su parte, Venezuela desde la llegada al poder del coronel Hugo Chávez Frías, ha puesto en práctica una estrategia de Respice Similia (mirar a los semejantes) sobre la base del liderazgo ejercido hacia la construcción de un bloque regional con algunos "Estados similares" en este caso mirando hacia "Mercosur".

En el análisis anterior se hace referencia a la posición ideológica adoptada por los gobiernos de ambos países en los últimos años, hay sin embargo abundante evidencia empírica que soporta el hecho de que las tensiones entre ambos países son de vieja data y se han vivido momentos de gran tensión en las relaciones bilaterales. Como consecuencia el cierre intermitente de las fronteras y el congelamiento de relaciones entre ambos países ha sido recurrente en la historia moderna de ambas naciones. En la revisión de las relaciones políticas y económicas es conveniente tomar en cuenta que han existido algunas diferencias en torno a la delimitación de fronteras entre Colombia y Venezuela. Desde 1952 ambos países han tenido serios desencuentros políticos como consecuencia de la soberanía y demarcación de aguas marinas y submarinas en lo que hoy se conoce como el Golfo de Venezuela. No obstante los desencuentros se han logrado mitigar aunque no se ha podido firmar un tratado definitivo que ponga fin en espacio y tiempo al diferendo.

Continuando con Ramírez (2011) los rumbos diferentes que tomaron Colombia y Venezuela, a pesar de ser naciones hermanas por contar con el mismo origen histórico, político, militar, étnico, cultural y religioso, durante los periodos de gobierno de los Presidentes Hugo Chávez y Álvaro Uribe, produjeron un nuevo campo de tensión ideológica, política y militar, similar al que se produjo durante la guerra fría, entre Alemania Oriental y Occidental o entre Vietnam del Norte y Vietnam del Sur o la que persiste hoy entre Corea del Norte y Corea del Sur. Así las cosas, estos procesos parecen mostrar un desplazamiento del eje de disputa entre capitalismo y socialismo hacia la Región Andina y más específicamente, a las dos orillas que separan los ríos Táchira y Arauca, en las que hoy en día, se da la común convivencia entre estos dos sistemas políticos y económicos.

De allí pues que Colombia y Venezuela no han conformado una estratégica asociación desde la perspectiva de ganar-ganar y buscando fórmulas que les garanticen una positiva inserción en el mundo actual. Tampoco han construido políticas de corto, mediano y largo plazo consistentes incluyendo a los sectores implicados en la relación binacional.

Dentro de este marco de relaciones se hizo evidente la polarización entre los presidentes Uribe y Chávez lo cual arrastró las relaciones a estar marcadas por la relación personal entre los mandatarios afectando la institucionalidad interna de ambos Estados, y debilitando la debida atención a los problemas sociales generados en la región fronteriza. Al transcurrir el tiempo los enfrentamientos escalaron en frecuencia y magnitud alimentadas por la concepción de gobierno diametralmente opuesta entre los mandatarios, un sistema democrático en Colombia y un régimen socialista estatizante en Venezuela. Es así que las relaciones económicas se afectaron de manera significativa impactando el flujo de comercio binacional 
al punto que para finales de 2009 las exportaciones colombianas a su vecino se redujeron en un $25 \%$.

Una vez culminado el mandato del presidente Uribe Vélez y ahora bajo la administración Santos se produce un cambio en la estrategia de la política exterior colombiana y busca recomponer las relaciones con sus países vecinos. Sin embargo con Venezuela la relación ha estado marcada por altibajos percibiéndose que las posibilidades de cooperación en el ámbito político y en el económico, son limitadas entre dos modelos muy distintos. Evidentemente las tensiones entre Caracas y Bogotá afectan las condiciones de vida de los pobladores que hacen vida cerca de la línea fronteriza, tanto colombianos como venezolanos muchos de ellos con doble cedulación dependen del intercambio de bienes, servicios e infraestructura. Esas realidades incrementan la sospecha mutua entre los gobiernos centrales para quienes la frontera es solo una línea y no la toman como una región con profundos nexos históricos, culturales, sociales y económicos. Dentro de este marco la imposición de trabas y barreras ha incrementado la informalidad y distintos contrabandos en las economías locales.

\subsection{Políticas cambiarias - consecuencias del diferencial cambiario}

\subsubsection{El Tipo de Cambio}

El tipo de cambio no es sino el precio de una divisa expresado en términos de otra y se lo determina mediante la interacción de los compradores y vendedores de divisas en el respectivo mercado, asumiendo que no existen fuerzas exógenas que interfieran o impongan restricciones en esa labor. Si esto es así, el tipo de cambio es fijado por la demanda y la oferta de una divisa, Cazar (2001). Como es verdad para la casi totalidad de bienes y en condiciones normales, la cantidad de una divisa extranjera demandada varía inversamente con su precio, es decir con el tipo de cambio de la divisa. En efecto, a medida que el tipo de cambio de una moneda extranjera aumenta, su cantidad demandada disminuye y si el tipo de cambio disminuye, su cantidad demandada se eleva, Cazar (2001: 13).

Por supuesto que esta situación no se presenta en la frontera Colombia- Venezuela dado que la existencia del control de cambio en Venezuela hace que se desvirtúe la relación oferta-demanda por la existencia de externalidades en la economía de la frontera donde se han implementado una serie de medidas y tomado decisiones que afectan el intercambio comercial.

Por otra parte la devaluación que no es sino la decisión de las autoridades monetarias de reducir el valor de la moneda nacional frente a una extranjera, involucra la depreciación de la moneda devaluada, pero es llevada a cabo mediante una decisión gubernamental que eventualmente puede ser impulsada por las fuerzas del mercado y/o por otras motivaciones económicas o aun políticas. De lo anterior se extrae que las motivaciones políticas pueden influir en la determinación del tipo de cambio de la moneda, es decir utilizar el tipo de cambio con motivaciones políticas.

En López (2011: 4) se señala que el desarrollo de la política fiscal en América Latina ha estado condicionada por factores de carácter externo, asociados a la evo- 
lución de los precios de materias primas y los cambios en los flujos de capitales de corto y largo plazo, y por factores de carácter interno, vinculados a la estructura económica de cada país y los vaivenes del escenario político. En efecto, tanto las políticas de gasto público, como la definición del marco impositivo han oscilado entre posiciones político-económicas de carácter conservador, las cuales han defendido medidas fiscales ortodoxas y afines a los intereses de los grupos económicos dominantes y, posiciones político-económicas de izquierda, para las cuales el Estado debe tener un rol director en las relaciones económicas y su influencia debe ejercer un efecto aglutinante en la sociedad.

Se plantea entonces el problema con la revaluación del peso colombiano y la fuerte devaluación del bolívar, esto hace que disminuya la capacidad de compra de los venezolanos y aumente la de los colombianos. Tal situación se ha volcado sobre los productos considerados de primera necesidad que escasean en Venezuela con lo cual se incrementaron los múltiples tráficos de las mafias transfronterizas quienes compran esos productos subsidiados y regulados para llevarlos a Colombia incrementando el contrabando de extracción de toda clase de productos sin importar que sean regulados o no incluyendo el combustible y derivados del petróleo.

\subsubsection{Fundamentos teóricos de la devaluación}

La devaluación es una decisión tomada por la autoridad monetaria en concordancia con el gobierno que consiste en un aumento determinado del tipo nominal de cambio, es decir, una modificación de la paridad de la moneda nacional en relación con las extranjeras, en virtud de la cual el valor externo de aquélla se reduce y también su valor interno. En general, el poder adquisitivo de la moneda devaluada en términos de bienes y servicios, tanto del mercado interno como del internacional, disminuye en cierta proporción. La devaluación es diferente de la depreciación de la moneda: esta resulta de un proceso inflacionario, de alza persistente y global de precios en el ámbito económico del país: es, por tanto, un fenómeno de mercado, en tanto que la devaluación es una decisión de política monetaria. En tal virtud, los productos del país de índole transable (que son o pueden ser objeto de comercio exterior) tienen la oportunidad de mejorar su posición comercial. En términos prácticos, esos productos adquieren ventaja en el mercado interno con respecto a los importados (Ver Maza Zavala: 28).

En ¿Por qué se devalúa?, Álvarez (2013) expone cuatro razones para devaluar: a) La política cambiaria puede utilizarse como un instrumento de política industrial cuando se trata de inducir y promover las transformaciones estructurales en el aparato productivo. De hecho, este es uno de los argumentos con los que se suele justificar la medida de devaluación: su efecto en la sustitución de importaciones y en la promoción de exportaciones; b) Política cambiaria como un instrumento de política antiinflacionaria. La política cambiaria también puede ser utilizada como un instrumento de política antiinflacionaria. De hecho, es lo que se hizo en los últimos años cuando a través del anclaje cambiario y la sobrevaluación del bolívar se utilizó justamente la política cambiaria y se subsidió el dólar para abaratar las importaciones; medida que al final tuvo efectos contraproducentes y muy negati- 
vos sobre el propio aparato productivo interno, el cual se vio desplazado por un creciente volumen de importaciones realizadas con un dólar subsidiado y cada vez más barato; c) Política cambiaria como instrumento de política fiscal, la política cambiaria, además de los usos antes comentados como instrumento de política industrial o de política antiinflacionaria, también puede tener aplicaciones y efectos muy concretos en materia de política fiscal. La devaluación le posibilita al fisco obtener más bolívares al vender el ingreso petrolero de más de \$ 95.000 millones en 2012 no a 4.30 sino a 6.30 bs/\$; d) Política cambiaria como instrumento de política exterior, una cuarta aplicación que puede tener la política cambiaria es como un instrumento de política exterior para impulsar procesos de integración económica.

En lo que respecta a Venezuela, aparte de lo señalado en el párrafo anterior que se adapta a la situación de ese país, el control de cambio se ha tomado como un arma política que difiere de los planteamientos teóricos tales como los expuestos en el párrafo anterior. Para ilustrar esto vale la pena rescatar las siguientes declaraciones: "El control de cambio en Venezuela no es una medida económica: el control de cambio en Venezuela, mis queridos compatriotas, es una medida política. Porque si nosotros quitamos el control de cambio, ustedes sacan los dólares y nos tumban. Mientras gobernemos tendremos que tener control de cambio”. Con esta precisión política, Aristóbulo Istúriz, gobernador del estado Anzoátegui y uno de los referentes del Partido Socialista Unido de Venezuela (PSUV), explicaba en julio de 2014 una de las verdades fundamentales de la crisis que hoy día se vive en Venezuela.

\subsubsection{Control de cambios}

Una vez un Gobierno toma la decisión soberana de establecer su política cambiaria, la polémica se establece en si el control de cambios es conveniente o no, dado que si por una parte evita la fuga de capitales y protege las reservas internacionales, por otra parte surgen desajustes tanto para los empresarios y la economía en general, en virtud que las empresas no podrán atender cualquier tipo de compromisos pendientes. Una vez que los desequilibrios se acumulan su impacto en la balanza de pagos tienden a multiplicarse obligando a fijar paridades cada vez más alejadas entre el mercado paralelo que surge como consecuencia de la escasa oferta de divisas y el precio referencial fijado por el Estado derivando todo esto en macro devaluaciones que afectan más a la economía del país que establece este régimen cambiario.

En el caso venezolano es evidente que la medida prolongada del control de cambio ha distorsionado la economía del país vecino. El manejo de su política económica ha llevado a escenarios de permanente inestabilidad del Bolívar y frecuentes devaluaciones, esto sin duda ha afectado la actividad comercial en sus zonas de frontera. En 2003 se fijó la tasa de cambio en 1,6 bolívares por dólar estadounidense, en 2011 se fijó una única tasa de 4,3 y desde 2013 se mantiene una tasa de 6,3 bolívares por dólar; esta es la denominada tasa oficial la cual presenta un diferencial considerable con la tasa paralela. 


\subsubsection{El Populismo desde una perspectiva económica}

Al estudiar el populismo desde una perspectiva económica López (2011: 6) señala que el surgimiento y evolución del populismo latinoamericano y su clara delimitación conceptual, constituye uno de los campos teóricos que ha generado mayor polémica entre los estudiosos de la realidad política y económica de la región durante las últimas décadas. A ello ha contribuido, lo voluble de sus características y las circunstancias internas y externas en las que se ha desarrollado. Por esta razón, es posible encontrar múltiples definiciones y matices a la condición populista de un gobierno, las cuales variarán en función del momento en que se produce el análisis y de las corrientes de pensamiento predominantes.

Sin embargo, el carácter populista puede ser entendido como una orientación económica que busca redefinir los mecanismos de asignación de una sociedad tomando prestados elementos del sistema de mercado y la visión del Estado como agente integrador. De este modo, el populismo tendría como objetivo primordial la mejora de la equidad social, especialmente en lo que respecta a la redistribución del ingreso, a partir del desarrollo de políticas económicas basadas en una amplia presencia del Estado en la economía, la imposición de severas restricciones a la actividad del sector privado, la preferencia por políticas fiscales donde predomine la influencia redistribuidora del gasto público y la escasa atención por la viabilidad de la estructura tributaria y/o los planes de endeudamiento a medio y largo plazos.

Es sobre este diferencial sobre el cual han presentado controversias voceros oficiales y no oficiales del gobierno venezolano. Ante esta realidad es conveniente hacer referencia al economista francés Frédéric Bastiat citado en Steimberg (2004) quien escribió "el hecho de que otros países tengan rocas en sus costas no es razón para lanzar rocas en nuestros puertos”, es decir, el hecho de que otros países distorsionen su producción con protección y subsidios no es razón para que distorsionemos la nuestra”.

\subsubsection{Economía oculta}

La economía oculta, llamada también subterránea, informal, o paralela, comprende no sólo actividades ilícitas, sino además los ingresos no declarados procedentes de la producción de bienes y servicios lícitos, tanto de transacciones monetarias como de trueques. Por lo tanto, la economía oculta comprende toda actividad económica que, en general, estaría sujeta a impuestos si fuera declarada a las autoridades tributarias. Una economía oculta próspera resta fiabilidad a las estadísticas oficiales sobre desempleo, población económicamente activa, ingresos, consumo, etc. Las políticas y los programas diseñados en el marco de estadísticas no fiables pueden ser inadecuados y contraproducentes. El crecimiento de una economía oculta puede precipitar un ciclo destructivo. Las transacciones de la economía subterránea escapan al sistema tributario, y de esa manera reducen el nivel de recaudación de impuestos. Si la base imponible o el cumplimiento tributario sufren erosión, los gobiernos pueden responder elevando las tasas impositivas, lo cual alienta una mayor fuga hacia la economía clandestina, y esto a su vez agrava las restricciones presupuestarias del sector público (Por otra parte, por lo menos 
dos terceras partes del ingreso obtenido en la economía oculta se gastan de inmediato en la economía oficial, en la cual producen un efecto estimulante bastante positivo). La expansión de la economía oculta puede hacer que trabajadores locales y extranjeros se sientan muy tentados a dejar la economía oficial (Ver Schneider y Enste, 2002).

En virtud de que la zona fronteriza conformada por el departamento Norte de Santander Colombia y el estado Táchira Venezuela se constituye en una región de intersección de dos economías, sometidas a las influencias de dos políticas económicas y dos políticas monetarias, aunado a un mercado paralelo alimentado por el control de cambios en Venezuela hace que el comportamiento de la economía y las actividades que de ella deriven favorezcan negocios especulativos con las divisas dado que las operaciones están sometidas a mayor riesgo, incluso en el caso venezolano penadas con cárcel.

En Martínez (2012: 22) se encuentra que el comercio ilegal con Venezuela a través de Cúcuta y la península de La Guajira es el más documentado en la literatura socio-económica colombiana, no obstante este fenómeno también se presenta en la frontera con Arauca. Los efectos derivados de la devaluación del bolívar frente al peso y demás políticas de ambos gobiernos han modificado el comercio entre las dos naciones; es de tal magnitud el fenómeno, que en las compras que se realizan en ciudades como San Cristóbal (Venezuela) ya se acepta la moneda colombiana como medio de pago según Mojica y Paredes (citados por Martínez, 2012). En la investigación se expone que la tercerización de la economía de la zona fronteriza colombiana (sustitución de actividades primarias como la agricultura y la industria por actividades de servicio como el comercio, el transporte y el turismo) se aprecia en la comparación de precios de lado y lado de la frontera para productos de primera necesidad. Aquí el diferencial de precios se constituye en un incentivo al contrabando, por cuanto permite ingresos extraordinarios a los participantes de la actividad.

El contrabando es el problema más importante en esta zona del Departamento, motivado por las diferencias cambiarias, esta situación se refleja en el comportamiento de los precios a ambos lados de la frontera y generó condiciones de desequilibrio orientando la demanda hacia bienes y servicios de origen venezolano y mostrando un aumento en los niveles de decomiso por parte de las autoridades aduaneras. Las ventajas comparativas que se suscitan en el manejo de la tasa de cambio, estimulan una corriente importante de contrabando, con pérdidas de mercado para la industria colombiana. Ante este escenario, las operaciones de compra y venta de la divisa venezolana en el mercado cambiario en la zona de frontera la inician los profesionales cambistas mediante el siguiente procedimiento: venden los bolívares a las casas de cambio, estos los consignan en sus cuentas en los bancos comerciales de Venezuela, allí son cambiados a dólares; los cuales son transados en Cúcuta para ser convertidos a pesos. En este proceso se presenta un diferencial en las diferentes tasas de cambio peso/bolívar, bolívar/dólar y dólar/ peso, estableciéndose así la utilidad del cambista. 
Es un hecho que la economía subterránea está presente en innumerables actividades, en todos los sectores económicos, y moviliza gran cantidad de recursos. Su tamaño y diversificación se aprecian al contabilizar las actividades descritas anteriormente. Por tratarse de actividades ilegales, no existen suficientes cifras disponibles y las estadísticas no reflejan el problema en su real magnitud. Cabe señalar que en 1995 año más reciente para el cual se obtuvieron datos confiables, el monto de las actividades contempladas ascendió a US\$11.910 millones, lo que da una idea de la gran cantidad de recursos que en Colombia provienen de la economía subterránea. Las corrientes de contrabando a través de la frontera han afectado negativamente la producción nacional, debido al paso ilegal de innumerables mercancías a través de los diversos tramos de frontera, tendiendo a un decomiso mayor.

Por esto el fenómeno del contrabando es un factor adicional en el entorno económico y social de los dos países esta actividad genera altos niveles de empleo mientras el diferencial de precios es un estímulo al comercio ilegal si se tiene en cuenta la significativa rentabilidad que genera la actividad económica respectiva.

\subsection{Consecuencias del diferencial cambiario en la zona fronteriza}

En Ramírez, Manzano, Zambrano y Nova (2013) se expone que en el sector externo, la oferta exportable del Departamento perdía valor continuamente en los mercados internacionales, evidenciando un deterioro en los términos de intercambio. Se indica en el estudio que entre los posibles factores que pueden dar respuesta a esta realidad se encuentra la persistente revaluación del peso colombiano entre los años 2002 y 2006. Se agrega que la crisis diplomática y fronteriza de finales de 2008 y 2009, condujo a que los empresarios norte santandereanos buscarán nuevos mercados. Es así, como en el año 2010 cuando se redujeron de manera drástica las compras venezolanas de productos colombianos, surgen mercados alternativos para la oferta exportable norte santandereana, tales como los mercados de Brasil, Panamá y Bélgica.

En el estudio se aprecia el impacto de las medidas venezolanas en las operaciones comerciales y en la economía del Departamento. La evidencia empírica refleja también como la estrategia comercial reaccionó ante ese escenario en busca de deslindarse parcialmente de la dependencia del mercado venezolano. Evidentemente esa reacción fue posible por la filosofía de mercado abierto existente en Colombia a diferencia de la visión estatista de la economía venezolana. Para ilustrar esta posición se reseña el trabajo Martínez (2008), allí se estudia el desempeño económico, tipo de cambio y relaciones estado-empresarios en Colombia y Venezuela.

El citado autor expone que entre 1980 y 2007 las mayores tasas de crecimiento permitieron que Colombia disminuyera la brecha que la separaba de Venezuela. Señala que dos factores fundamentales que ayudan a explicar estos resultados son el manejo del tipo de cambio y las relaciones Estado-empresarios, cuyo comportamiento estuvo determinado por las condiciones históricas iniciales de cada 
país, lo cual confirma la tesis de que la existencia de costos de transacción hace que la historia sea determinante en la evolución de las instituciones de acuerdo con North (citado por Martínez, 2008). Otro factor fue el fortalecimiento relativo de las instituciones en Colombia, que junto con las buenas relaciones entre el Estado y los empresarios se tradujo en una estrategia de desarrollo coherente que mantuvo continuidad. Por último, señala que el deterioro de las relaciones Estado-empresarios y de las instituciones que se ha producido en los últimos años en Venezuela probablemente tendrá un fuerte efecto negativo en el crecimiento económico de largo plazo.

En el caso venezolano, su modelo económico vigente se basa en un rígido control de cambio de divisas que le impide a las empresas adquirir las materias primas y los productos necesarios para su funcionamiento. Tanto las empresas venezolanas como el propio Gobierno han perdido la confianza e importantes líneas de crédito de los mercados internacionales. Otro factor del modelo económico vigente es el control estatal del precio de venta al consumidor. Por esto se ha desarrollado un aparato burocrático muy costoso para el Estado que apela a normas coercitivas criminalizando la actividad económica donde se incluyen amenazas de sanciones penales. Se explica así que han ahuyentado del país a inversionistas extranjeros y desalentado la producción nacional. Dicho de otro modo el sector privado es atacado constantemente.

Dentro de este marco en "Comercio a Venezuela cuesta abajo" (2014), de acuerdo con datos de la Asociación Nacional de Exportadores de Colombia, Analdex, las ventas externas a Venezuela entre enero y noviembre de 2013 cayeron hasta un $10.8 \%$. Estas pasaron de US $\$ 2.380$ millones a US $\$ 2.123$ millones en dicho periodo, y las expectativas para 2014 no son las mejores.

Esta situación se profundizó a raíz de las sucesivas devaluaciones que han experimentado el Bolívar en los dos últimos años y la permanencia del control de cambio. Se plantea en el artículo que "todo corre por cuenta de los mecanismos cambiarios que están poniendo en jaque a los importadores venezolanos que se quedarán sin disponibilidad de recursos para cumplir sus compromisos comerciales”.

\subsubsection{Tasa de Cambio en la frontera}

La tasa de cambio en la zona fronteriza, entre Venezuela y Colombia sigue en continua variación, ya que la cotización de la moneda del país vecino frente al peso colombiano llegó a tocar un mínimo histórico en las casas de cambio de la frontera, al ubicarse en \$0,010 en marzo de 2015, el precio del bolívar frente al peso colombiano ha estado a la baja, no solo desde inicios de año, sino desde el segundo semestre de 2014 tal como lo planteó Fernández (2015). Desde julio del año pasado la tasa de cambio del bolívar en la frontera empezó a presenciar una tendencia a la baja, al pasar de $\$ 0,026$ y llegar a $\$ 0,014$ al finalizar el año, monto en el que estuvo oscilando durante los primeros dos meses de 2015, en los cuales se movía entre $\$ 0,014$ y \$0,013 hasta llegar su punto más bajo el pasado 6 de marzo. El comportamiento se muestra en la figura 1. 
Figura 1. Tasa de cambio del bolívar en la frontera años 2014-2015 marzo

\section{Tasa de cambio del bolívar en la frontera 2015 (Cifras en pesos)}

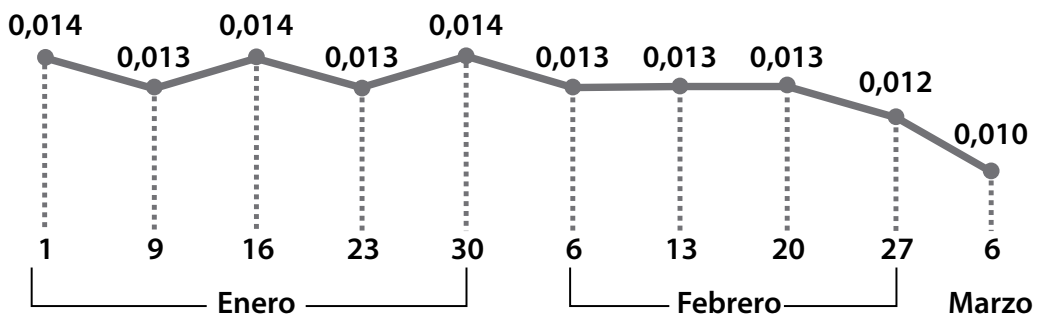

Tasa de cambio del bolívar en la frontera 2014 (Cifras en pesos)

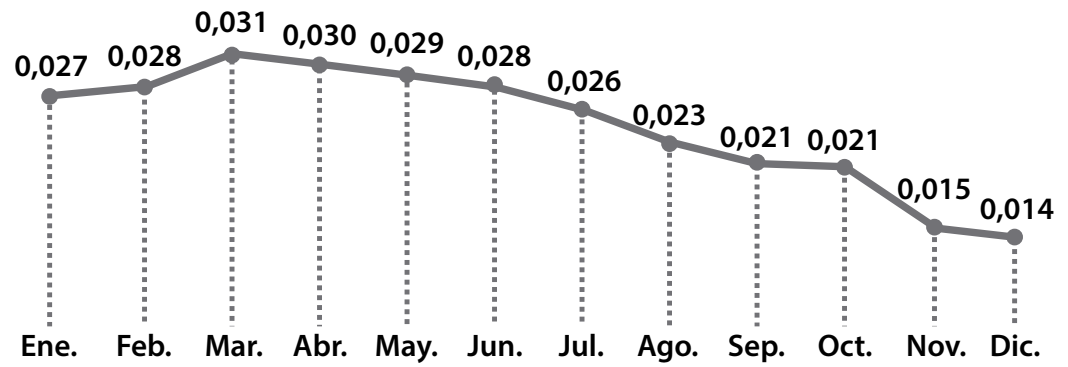

Fuente: Fernández (2015)

Asimismo el comportamiento de la tasa oficial se muestra en la figura 2.

Figura 2. Tasa de cambio oficial Peso Colombiano-Bolívar entre 2011-2015 marzo

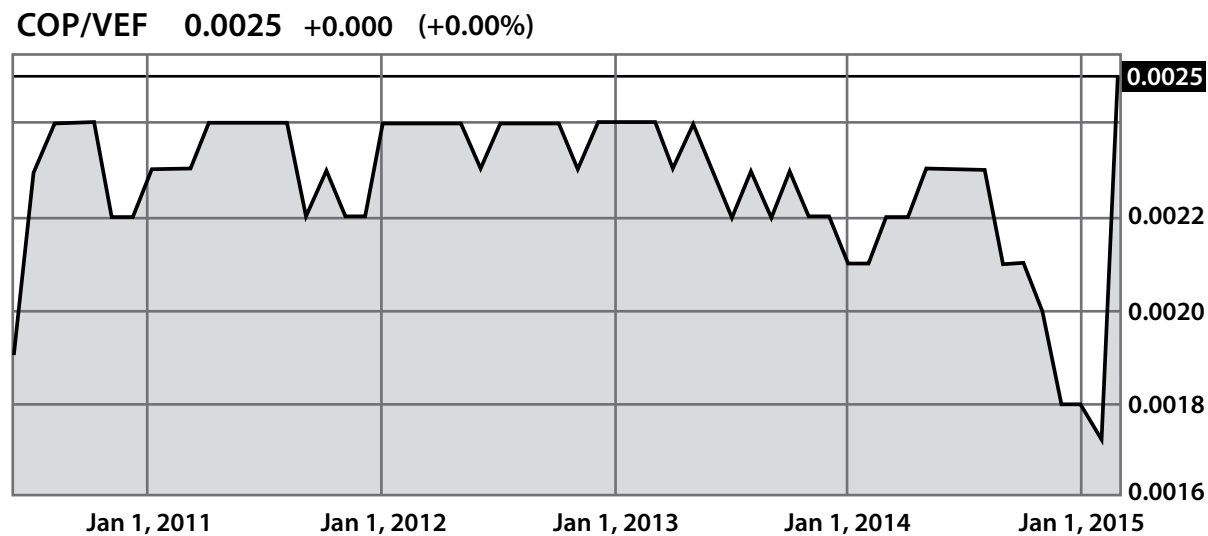

Fuente: Investing.com. 
En una trasformación a valores oficiales un (1) Peso Colombiano es equivalente a unos Bs. 0.0025, un (1) Bolívar Venezolano es equivalente a 407,06 pesos aproximadamente, en realidad la situación es otra. Según la investigación que se ha realizado, por cada bolívar dan al comprador entre 11 y 12 pesos a la fecha 23 de marzo 2015.

En un mercado cambiario marcado por una amplia oferta y una reducida demanda, la cotización del bolívar se encuentra en caída libre en las casas de cambio de la frontera con Colombia. Esto es consecuencia no solo de la inflación existente, sino de la expectativa de que Venezuela va hacia una hiperinflación. Para el venezolano son más atractivas otras monedas, incluso el peso, antes que el propio bolívar. Se estima que el valor de la moneda local se mantenga en descenso, en vista que el Gobierno venezolano apuesta por mantener inalterable su paridad cambiaria.

El diferencial entre los dos tipos de cambio (oficial y de mercado) ha permitido la especulación y el arbitraje a una escala masiva. Existen diversas formas para hacer ganancias basadas en esta práctica una de ellas consiste en enviar remesas desde Venezuela a Colombia. Otra de las modalidades consiste en el uso de tarjetas de crédito en el exterior, en Colombia se hacen compras ficticias que se liquidan en Venezuela a la tasa oficial (6,3 bolívares por dólar). Como las compras son ficticias, quienes las realizan reciben el monto de las mismas en pesos en lugar de mercancía, luego de pagar una comisión al local que facilitó dicha transacción. Posteriormente, los pesos que se obtienen por estas compras son convertidos a bolívares.

Las ganancias por el diferencial cambiario son bastante significativas y por ello llevan a una masa de la población a efectuar este tipo de operaciones en forma rutinaria. Evidentemente este mecanismo afecta a la economía venezolana dado que se convierte en una fuente de fuga de divisas y en el caso colombiano genera impactos sobre la economía en virtud que se está alimentando una economía ficticia.

\subsubsection{Política cambiaria Colombia y Venezuela}

En Rodríguez (2014: 4) se señala que el hecho que en el vecino país se tenga un régimen de tasa de cambio fija y en general, la política cambiaria sea manejada por el gobierno bolivariano (además de la existencia de otros tipos de cambio paralelos, pero oficiales, todos anclados al dólar estadounidense), contrasta con el régimen de tipo de cambio flexible en Colombia; y en espacios geográficos como la frontera, con su punto más neurálgico en la ciudad de Cúcuta (del lado colombiano), genera espacios para el arbitraje y la especulación, a tal punto que termina por afectar todo el aparato productivo fronterizo. Existe también mercado de cambio no oficial o paralelo que en los mercados de la frontera responden a un sistema más o menos de libre mercado constituido por un bolívar muy devaluado el cual impacta al comercio al menudeo.

En Colombia, actualmente existe una categoría particular de tasa de cambio flotante que se denomina tasa de cambio flexible. Ésta tiene como fundamento un sistema cambiario de tasa de cambio flotante, sin embargo, esta tasa no es completamente libre, porque en un punto determinado, buscando evitar cambios repentinos y bruscos en el precio de la moneda, las autoridades pueden intervenir en el mercado. La diferencia de una tasa de cambio flotante sucia con una tasa de cambio fija es que, en este sistema de tasa de cambio, no se establecen unas 
metas fijas por encima o por debajo de las cuales el valor de la moneda no puede estar. Uno de los motivos para que los países tengan tipo de cambio flexible, como Colombia, es que sus bancos centrales (en teoría) sean independientes en cuanto a decisiones de política monetaria se trata.

De hecho es esta modalidad de tipo de cambio la que ha permitido el manejo del diferencial cambiario en la frontera dado que se rige por las condiciones del mercado al fijar la paridad fronteriza en relación a la convertibilidad del peso frente al dólar norteamericano y sobre la cual han recaído críticas desde el gobierno venezolano.

\subsubsection{Consecuencias del diferencial cambiario en la zona fronteriza}

El tipo de cambio de la moneda venezolana con respecto a la colombiana afecta a las dos naciones. Los comerciantes o habitantes venezolanos tendrán una mayor dificultad a la hora de realizar sus compras en Colombia, en virtud de que se tendrá que cambiar mayor cantidad de bolívares para obtener la misma cantidad de pesos colombianos cada vez que la cotización cae.

Fernández (2015) analiza un escenario en la frontera, si un venezolano cambia el valor de su salario mínimo mensual ( 5.644 bolívares) a pesos colombianos en la frontera, con la tasa que se manejaba iniciando 2015 podía obtener $\$ 70.000$, mientras que si hace este mismo cambio hoy recibiría $\$ 56.440$ (menos de $10 \%$ del salario mínimo equivalente a $\$ 644.350$ ), se indica en el artículo que en palabras del investigador del Observatorio de Venezuela de la Universidad del Rosario, Ronal Rodríguez, "Mientras la economía venezolana no sea regular, sino que se cometan estos cambios fuertes será mucho más complicado estrechar las relaciones comerciales, porque no se sabe cuándo sube o baja el bolívar. Los venezolanos que importan lo hacen a tasas preferenciales y el comercio entre Colombia y Venezuela se ha desplomado porque no hay garantías de pago por parte de Venezuela. No hay seguridad jurídica".

Con el cambio de la moneda ubicado en $\$ 0,010$ parte del comercio del país en ciudades como Cúcuta se ven afectadas, debido a que se fomenta el aumento de contrabando que se presenta en la frontera. Se estima que el $40 \%$ de productos venezolanos se esfuman en la porosa línea fronteriza y se calcula un contrabando de USD 3.600 millones anuales hacia Colombia.

El Gobierno venezolano tomó la decisión a partir del lunes 11 de agosto de proteger el abastecimiento de productos de la canasta familiar a la población venezolana, incurriendo en la estrategia de cierres temporales de los puentes internacionales Simón Bolívar y Francisco de Paula Santander, la acción se deriva del desabastecimiento que genera la extracción de mercancías de consumo masivo y gasolina hacia la frontera y de la dificultad de producción interna, incluso de la importación de materia prima para la elaboración de productos básicos de consumo. También de un diferencial cambiario en frontera que hace muy atractivo la comercialización de productos en el mercado de la ciudad de Cúcuta y su área metropolitana.

Sánchez (2014) cita a Barrera quien analizó los efectos de las decisiones económicas venezolanas sobre la economía cucuteña, teniendo en cuenta las devaluaciones del bolívar, los incidentes diplomáticos entre los dos países y las reformas económicas implementadas por el gobierno venezolano. La autora concluye que 
dichas fluctuaciones sumieron a la ciudad en una profunda crisis, reflejando la sensibilidad de su economía a choques externos provenientes del vecino país. En referencia a los efectos de la devaluación del bolívar, Sánchez (2014: 26-29) concluye que la inestabilidad cambiaria hace que el modelo de desarrollo de las economías fronterizas, basado en el intercambio comercial con economías externas cercanas, no sea sostenible mientras perdure el desequilibrio macroeconómico. Esto se debe a que estas van a estar sujetas a choques cambiarios (tanto positivos como negativos) derivados del manejo de la política económica del país vecino, lo que genera volatilidad en el ciclo económico.

Por su parte Rodríguez (2014: 42) argumenta que a mediano y largo plazo, suponiendo la frontera como un todo, los resultados de las empresas tienden a profundizarse y propagarse en la economía revirtiendo el resultado del corto plazo, es decir, a la larga las devaluaciones sostenidas del bolívar tienden a perjudicar la economía local porque en últimas el consumidor depende de la actividad productiva en general dado que los hogares derivan su ingreso de salarios o utilidades de las empresas.

Se plantea entonces que el escenario de devaluación del bolívar y debilitamiento de la actividad productiva se traduce a mediano plazo en menor demanda de mano de obra que consecuentemente se refleja en una menor capacidad de compra que contrarresta el temporal beneficio de los consumidores. Es por ello, que las políticas económicas generalmente se enfocan en el sector productivo que indirectamente impactan en toda la sociedad. De hecho el aumento en el desempleo favorece un incremento de la informalidad laboral en una región donde sus habitantes pueden dedicarse a actividades económicas propias de frontera como el contrabando y el aprovechamiento del diferencial cambiario por el cambio de divisas.

\subsection{Posiciones encontradas en ambos países respecto al diferencial fronterizo}

Se reproducen algunas de las muchas opiniones, comentarios y reseñas encontrados sobre la región fronteriza Norte de Santander Colombia y el estado Táchira en Venezuela, donde se hace referencia al diferencial cambiario y el comportamiento de la economía. A continuación se clasifican las opiniones desde ambos países considerando tanto a afectos como a opositores al gobierno.

\subsubsection{Posiciones en Colombia}

En Colombia, Martínez (2008) señaló que el deterioro de las relaciones Estadoempresarios y de las instituciones que se ha producido en los últimos años en Venezuela probablemente tendría un fuerte efecto negativo en el crecimiento económico de largo plazo.

En efecto el autor adelantó en el estudio las consecuencias que tendría para la economía venezolana la hipertrofia del estado al convertirse en un estado empresario y limitar la libertad económica del sector productivo lo que llevó a la economía venezolana a una situación de estancamiento y debilitamiento del sector productivo. Esto aunado a la política del estado venezolano de generar una economía de puertos 
y la caída de los ingresos ha generado una crisis que se refleja en el incremento del índice de escasez de productos básicos en Venezuela.

Por su parte García (2010) señala que Venezuela es el caso latinoamericano más patente y visible de la vulneración a la libertad económica y por consiguiente de desconocimiento de las libertades políticas y civiles de los ciudadanos. Al día de hoy, el resultado de sus revolucionarias medidas económicas es contrario a lo que el equipo de gobierno afirma con vehemencia. Venezuela está distanciándose frenéticamente de la meta que toda sociedad moderna persigue al menos en el ámbito económico, la prosperidad económica y el bienestar de todos los individuos. Al mismo tiempo la violencia generalizada y la incompetencia del gobierno central para resolver los problemas más urgentes conducen al país a una condición nada deseable de Estado fallido.

De hecho analistas y declaraciones recogidas en la prensa también sometida a un régimen de autocensura sostienen que el control de cambio del gobierno venezolano, la notoria escasez de alimentos, medicinas y repuestos, aunado a una inflación galopante que la coloca como la más alta del mundo y la disminución del precio del petróleo agudiza la crisis económica que se vive en Venezuela.

Lozano (2014) en "Frontera caliente: entre Venezuela y Colombia, paraíso del contrabando", expone que la frontera concentra y amplifica casi todos los males nacionales de Venezuela: corrupción, escasez de alimentos, desabastecimiento, una inflación compulsiva a ritmo de récord mundial, la plaga de la violencia desmedida, la imparable escalada del dólar paralelo y las largas esperas en las estaciones de servicio (entre tres y cuatro horas). Un vía crucis, éste sí, exclusivo de la zona.

En nuestra opinión resulta claro entonces que el modelo económico socialista que ha adoptado el gobierno venezolano ha generado dificultades económicas que se agudizaron a comienzos de 2015. Mientras que economistas realizan propuestas para cambiar el modelo económico y establecer gradualmente una economía de libre mercado, el Gobierno venezolano insiste en mantener el modelo socialista existente. De este modo, el intento de los dos gobiernos por racionalizar lo irracional no frena la vorágine de los grandes negocios limítrofes entre ellos el cambio de divisas gracias al control de cambios impuesto por el gobierno de Hugo Chávez en el año 2003.

\subsubsection{Posiciones en Venezuela}

En declaraciones recogidas en Venezuela de los medios de comunicación sean escritos, audiovisuales o electrónicos es un común denominador las dificultades por las que está atravesando ese país. La incidencia de la inflación que está entre las más altas del mundo, sucesivas devaluaciones del Bolívar, agotamiento de las reservas internacionales, control total del aparato productivo, criminalización de la actividad comercial amenazando con cárcel a productores y distribuidores de productos incidiendo en caída de la producción han propiciado un evidente deterioro de la calidad de vida del venezolano y ha puesto sobre el tapete el debate sobre la concepción filosófica del modelo económico del gobierno entre un sistema socialista o comunista estatizante y empobrecedor o un modelo que los voceros del gobierno califican de exitoso. 
En el artículo "Venezuela: el socialismo del siglo XXI y la enfermedad holandesa como estrategia económica"2, se publica que los ingresos externos, más de un millón de millones de dólares no alcanzaron y no alcanzarán, y como la dependencia del ingreso petrolero es total y las políticas fiscales y monetarias son expansivas, la inflación y la pobreza serán el resultado inevitable. Un gasto desmedido y sin contraparte en la producción, una expansión irresponsable de la liquidez monetaria y la eliminación casi total del parque industrial, no podían tener otro destino. Esto es todo lo que puede mostrar el socialismo del siglo XXI en materia económica. Los elementos que enraízan en esta conducta son idénticamente iguales a aquellos que caracterizan al capitalismo tardío llevados a su apoteosis superior: positivismo, funcionalismo, determinismo y un desprecio absoluto por la democracia y los ciudadanos. Un vulgar proyecto de vocación totalitaria, nada más. Otra oportunidad perdida.

En un informe que efectuaron 60 economistas de Venezuela (22 de enero de 2015) resaltan las causas de la crisis actual, pero también elaboran una serie de propuestas que deben poner en práctica de inmediato para revertir la situación actual. Sugieren que se establezca una economía de mercado con fuertes instituciones sociales y económicas, donde todos los sectores nacionales, el sector privado y público tengan abierta las puertas a participar. Sostienen que el control de cambio con múltiples tasas que se ha mantenido por razones políticas ha sido el centro de una crisis de valores en el país, de afán de riqueza fácil. Por lo tanto es importante desmontar el régimen de control de cambio como objetivo central dentro del plan económico, fiscal, monetario y financiero para lo cual es fundamental crear las condiciones económicas y sociales para mejorar la producción, distribución y comercio de bienes y servicios, señaló el informe.

Según Becerra (2016), el presidente Nicolás Maduro en la entrega de la Memoria y Cuenta, en enero de 2015, afirmó que se intensificaron las condiciones de crisis y guerra económicas debido al "ataque monstruoso a la moneda, al sistema de cambio y a la imposición de vulneración de la vida monetaria especulativo al margen de las leyes de la economía". Hizo referencia a la Inflación y "guerra económica": "Esto es una estrategia imperial con un objetivo, la búsqueda del quiebre de las banderas socialistas que se han levantado desde Venezuela". En resumen el Gobierno venezolano insiste en mantener el control de cambio y los controles de la distribución de alimentos y en mantener el control de precios de los mismos, así como la distribución de comercialización, tanto del sector privado como del público.

Por su parte Mendoza (2014) expone que el sistema de control de cambios ya es un sistema totalmente anacrónico, cumplió su ciclo real, y debe ser revisado científica y políticamente. No es posible sostener la economía nacional con 4 tipos de cambios, máximo cuando son los más altos valores los que determinan la estructura de costos y se adquieren en los más bajos valores. De allí, que se está generando una enorme inflación, desabastecimiento y distorsiones en la oferta de bienes y servicios. Los daños al país son evidentes: hemos alcanzado una de las

2. (www.petroleoamerica.com, 2015). 
inflaciones más alta en el mundo en menos en un año; el costo de la cesta básica subió más de un $70 \%$.

Se encontró en Hernández (2014) que dos mil millones de dólares es la cifra que estima en pérdidas anuales por contrabando de extracción el ministro del Poder Popular para Petróleo y Minería, Asdrúbal Chávez. Todo ello sucede en virtud de la brecha que existe entre la moneda venezolana y la colombiana. Señala Hernández que el economista y abogado colombiano experto en el tema fronterizo Daniel Libreros Caicedo explica que la "perversión cambiaria tan pronunciada sucede por especulación, porque las casas de cambio fronterizas establecen una hinchazón artificial que les permite capturar más ganancia por contrabando. La Superintendencia Financiera de Colombia debería regular esta práctica, pero al ser un mercado no visible, aunado al peso político y económico de estas mafias es muy difícil controlarla”. Se plantea entonces el problema que cuando se restringen mucho los mercados cambiarios, surgen mercados paralelos donde los agentes económicos buscan satisfacer las necesidades que les están siendo restringidas para la obtención de divisas. Al derivar esto hacia el incremento del diferencial cambiario a medida que los controles permanecen en el tiempo se presentan distorsiones que son aprovechadas por los agentes del mercado y aparece una economía ilegal que se va a beneficiar de esas distorsiones.

En atención a las posiciones anteriores es pertinente señalar que de acuerdo a la teoría económica mantener una economía bajo control por largos períodos de tiempo conduce a serios desequilibrios que al final desembocan en desajustes en materia de precios, salarios, escasez de bienes y servicios, malestar en los consumidores por la falta de productos en los mercados, que obligan para corregir los desequilibrios a la aplicación de severos programas, conocidos como programas de ajuste, a fin de restablecer los equilibrios. Aunado a esto muchos analistas han señalado el carácter político que conlleva el control de cambio para ellos el control de cambio más que una medida de protección o de anclaje cambiario es una medida de control de las divisas que se generan asignándose el Gobierno la facultad de determinar qué se importa y cuánto a lo que agregaríamos y cuando.

Es destacable también señalar que los objetivos de la aplicación de los controles no "han sido alcanzados", entre ellos, la recuperación de las reservas, la estabilidad del tipo de cambio paralelo y de la inflación. Resulta claro que en Venezuela se suman todos los males que la teoría económica y financiera han alertado a través de los años y a los cuales se les ha hecho caso omiso convirtiéndose así en la tormenta prefecta conformada por una debacle económica, una devastación institucional y una fractura del aparato de seguridad estatal.

Para Venezuela los aspectos clave que obligaron al cierre de la frontera se resumen en cuatro puntos lo que el presidente Nicolás Maduro ha llamado una "nueva frontera de paz en la que los ciudadanos ya no sean víctimas del modelo capitalista, neoliberal y paramilitar que se trasladó desde Colombia al país”. Esto se resume en: 1) El contrabando de combustibles 2) El contrabando de alimentos y bienes básicos 3) La ofensiva cambiaria 4) La violencia paramilitar.

El análisis de las posiciones reseñadas no hace más que corroborar la hipótesis sostenida por este autor en cuanto a las asimetrías sobre economía fronteriza. Se 
plantea el problema y se hace énfasis en que la economía de la frontera está conformada por economías asimétricas legales e ilegales, donde la respuesta del Estado venezolano históricamente ha sido errónea y ha intentado resolverla con represión.

\section{CONSIDERACIONES FINALES}

En términos globales el comportamiento del consumidor en ciudades fronterizas presenta un patrón común dado por los beneficios que pueda obtener en el intercambio comercial. Se confirma la tesis que mientras más barreras se coloquen a la relación fronteriza esto trae como consecuencia el aumento de prácticas ilegales lo cual alimenta la corrupción en funcionarios civiles y militares encargados de controlar el flujo transfronterizo.

Cabe considerar que mientras Colombia se enfoca en una relación cercana con Estados Unidos, Venezuela ha mirado hacia el Sur buscando establecer alianzas con Mercosur marcando distancias aparentes con los Estados Unidos donde las controversias mediáticas no se reflejan en la relación comercial, es un hecho que Venezuela mantiene con esa nación intercambios comerciales muy importantes a pesar del discurso donde refleja continuos enfrentamientos. En efecto se confirma que el Departamento Norte de Santander en el año 2013 presentó una situación económica crítica la cual no se puede considerar imputable solo a la devaluación del bolívar, también influyó el diferencial cambiario más aún cuando la economía se sustenta en el comercio relacionado más con Venezuela que hacia el interior del país. Dentro de este marco se considera inaplazable reenfocar la estrategia de desarrollo del Departamento Norte de Santander para romper la tradicional dependencia del mercado venezolano. Siendo así se requiere un cambio en la perspectiva bajo la cual ha sido observado y tratado desde el gobierno central con un criterio de Estado-Nación y no desde el punto de vista de región fronteriza se podría tomar los correctivos requeridos en la región.

Aunque se hace referencia a la posición ideológica adoptada por los gobiernos de ambos países como detonante del conflicto hay abundante evidencia empírica que soporta el hecho de que las tensiones entre ambos países son de vieja data y anteriormente a los gobiernos de Uribe y Chávez se vivieron momentos de gran tensión en las relaciones bilaterales. Al analizar las tensiones entre Caracas y Bogotá se observa que entre algunas de sus manifestaciones se afecta las condiciones de vida de los pobladores que hacen vida cerca de la línea fronteriza, tanto colombianos como venezolanos dependen del intercambio de bienes, servicios e infraestructura. Para los gobiernos centrales quienes consideran la frontera como solo una línea esas realidades incrementan la sospecha mutua entre ellos y en consecuencia no la toman como una región con profundos nexos históricos, culturales, sociales y económicos. Siendo así, la imposición de trabas y barreras contribuye a incrementar la informalidad y distintos contrabandos en las economías locales.

Se plantea entonces la existencia del control de cambio en Venezuela como factor incidente, dicho control de cambios ha hecho que se desvirtúe la relación oferta-demanda de divisas tal como se documenta en la teoría de comercio internacional. En la frontera se han implementado una serie de medidas y se han tomado decisiones que afectan el intercambio comercial. En el caso venezolano, 
la medida de control de cambio en una primera etapa logró controlar la salida de divisas. Pero al no corregir las fallas estructurales tal como la alta dependencia de las exportaciones petroleras y su valor, que varía de acuerdo con el comportamiento de los mercados globales, repercute tanto en las cuentas fiscales como en la oferta de divisas para el mercado interno. Bajo esta premisa, las externalidades a la economía en Venezuela han producido desajustes que se han trasladado a la zona de frontera donde existe una economía de mercado que se ha visto afectada por el diferencial cambiario que ha propiciado el contrabando y otras actividades de economía oculta que perjudican al departamento Norte de Santander y permea hacia el interior del país. Es un hecho que en Venezuela el control de cambio se ha tomado como un arma política que difiere de los planteamientos teóricos donde se explican los fundamentos que soportan la implantación del mismo como elemento corrector de distorsiones de corto plazo en la economía. Se plantea entonces que en el caso venezolano es evidente que la medida prolongada del control de cambio ha distorsionado la economía del país vecino. El manejo de su política económica ha llevado a escenarios de permanente inestabilidad del Bolívar y frecuentes devaluaciones, esto sin duda ha afectado la actividad comercial en sus zonas de frontera.

Aunado a esto la revaluación del peso colombiano y la fuerte devaluación del bolívar ha disminuido la capacidad de compra de los venezolanos y ha aumentado la de los colombianos en Venezuela. Por ello la demanda se ha dirigido a los productos considerados de primera necesidad que escasean en Venezuela y son subsidiados por el gobierno venezolano, contribuyendo así a incrementar los múltiples tráficos de las mafias transfronterizas acrecentando el contrabando de extracción de toda clase de productos sin importar que sean regulados o no, incluyendo el combustible y derivados del petróleo. El contrabando no solamente se hace a gran escala, también hay nuevas modalidades: los conocidos como "bachaqueo", que comercian con dos o tres productos y los llamados maleteros, que transportan la carga a través del río.

Entre los sectores afectados en Colombia por el incremento del contrabando influenciado por el diferencial cambiario se encuentra el sector salud dado que un porcentaje muy alto de los impuestos al consumo de cigarrillos, bebidas alcohólicas y cervezas que recaudan los departamentos se destina a la salud de sus habitantes. Pero si la gente los consume de contrabando, los recursos no llegan a su destino final: los hospitales.

En la investigación se encontró que los trabajos académicos corroboran la transmisión del efecto cambiario a la economía de la frontera colombo-venezolana impactando en los indicadores de la región. Entre los hallazgos se encontró que en un escenario como el actual donde el bolívar se devalúa, la tasa de cambio se reduce (se pagan menos pesos por bolívar) y por lo tanto aumenta la brecha de desempleo: la tasa de desocupación de Cúcuta es considerablemente mayor a la del total nacional. En la revisión se encontró que la devaluación tiende no sólo a afectar la desviación de la inflación cucuteña y que no es la tasa de cambio oficial la mayor determinante para el comercio fronterizo sino la tasa de cambio de mercados paralelos como las casas de cambio. 
Dado que la zona fronteriza conformada por el departamento Norte de Santander, Colombia y el estado Táchira, Venezuela se constituye en una región de intersección de dos economías, sometidas a las influencias de dos políticas económicas y dos políticas monetarias, aunado a un mercado paralelo alimentado por el control de cambios en Venezuela hace que el comportamiento de la economía y las actividades que de ella deriven favorezcan negocios especulativos con las divisas dado que las operaciones están sometidas a mayor riesgo e incluso en el caso venezolano penadas con cárcel. El diferencial entre los dos tipos de cambio (oficial y de mercado) ha permitido la especulación y el arbitraje a una escala masiva. Ahora bien, no se cuenta con cifras aproximadas del impacto de la economía oculta en la región de fronteras por el diferencial cambiario dado que la información obtenida careció de soporte empírico, no obstante según voceros del gobierno venezolano en lo que respecta al combustible las pérdidas económicas suman 200 millones de dólares al año y hay un significativo impacto sobre la productividad ya que deben hacerse colas de al menos 4 horas. Por tratarse de actividades ilegales, no existen suficientes cifras disponibles y las estadísticas no reflejan el problema en su real magnitud, en 1995 año más reciente para el cual se obtuvieron datos confiables el monto ascendió a US\$11.910 millones, lo que da una idea de la gran cantidad de recursos que en Colombia provienen de la economía subterránea.

Por lo demás se verificó el impacto de las medidas venezolanas en las operaciones comerciales y en la economía del Departamento Norte de Santander pero también se encontró que la estrategia comercial reaccionó ante ese escenario en busca de deslindarse parcialmente de la dependencia del mercado venezolano. Esa reacción fue posible por la filosofía de mercado abierto existente en Colombia a diferencia de la visión estatista de la economía venezolana. Al convivir la región fronteriza ante dos modelos económicos queda expuesta a los desajustes se suman las transformaciones de los dos países y el fortalecimiento de la economía de frontera, como lo señala Carrión (2011) sustentada en la asimetría complementaria de los Estados colindantes. La economía de frontera es parecida a una "economía de enclave", pero muy especial, porque no explota un solo producto o servicio de un capital monopólico, sino que es un complejo diversificado de intercambios comerciales, legales e ilegales, que tienen enlaces superiores a los territorios transfronterizos. Se trata de una economía invasiva que hace metástasis en el sistema penal, en la economía, en la sociedad y en la política, así como también desarrolla prácticas delictivas encaradas por nuevos actores. La economía de frontera integra dos o más economías asimétricas por ser funcionales entre sí.

Resulta claro que el modelo económico socialista que ha adoptado el gobierno venezolano ha generado dificultades económicas que se agudizaron a comienzos de 2015. La evidencia muestra que en la región fronteriza no existe consenso entre los actores en cuanto a la característica del mercado cambiario. Mientras para unos es consecuencia del mercado y de los desequilibrios originados por las políticas del gobierno venezolano, para otros es consecuencia de la especulación y del accionar de las mafias de la frontera. La perspectiva que aquí adoptamos señala que en Venezuela se suman todos los males que la teoría económica y financiera ha alertado a través de los años y a los cuales se les ha hecho caso omiso convirtiéndose así 
este escenario en la tormenta perfecta, conformada por una debacle económica, control de precios y control de cambio, escasez, colas y precios altísimos.

Algunas voces críticas señalan que la gran mayoría de los políticos venezolanos, de antes y de ahora, han tenido una miopía recurrente en confundir, a veces inconscientemente, a veces ex profeso, lo que son las consecuencias de un problema con sus causas. Por esto, eso los lleva a defender sus razonamientos de una manera sesgada, acomodaticia, con el propósito de convencer a sus electores de que están obrando en función del bien público. Por ello, a menudo las medidas que toman para la solución de un determinado problema están cargadas de demagogia o populismo. ¿No podemos competir con las importaciones de papa colombiana? prohibamos las importaciones ¿Qué hacemos con el problema del contrabando en la frontera y el desabastecimiento interno? cerremos la frontera. ¿El régimen de tipo de cambio flexible de Colombia nos hace daño? exijamos a su gobierno que instrumente un control de cambio. Otra característica del político venezolano es su incapacidad para pensar no digamos en el largo plazo, un horizonte de veinte o treinta años, ni siquiera le importa el mediano plazo. La mayoría se concentra en soluciones de corto plazo, las que tienen más factibilidad política, a menudo al margen de su viabilidad técnica y financiera. Las medidas tomadas generalmente tienen un efecto positivo pasajero, pero no garantizan que el problema se solucionará. Frecuentemente, las dificultades regresan exacerbadas, causando más daño del que originalmente causaron.

La evidencia venezolana indica que los controles de capital se han utilizado para mantener sobrevaluado el tipo de cambio real y aplicar políticas macroeconómicas expansivas durante períodos excesivamente largos y por lo tanto insostenibles. Siendo así, el manejo del diferencial cambiario en la frontera desde la perspectiva venezolana está privando la política sobre lo económico mientras del lado colombiano se está dejando que fluctúe de acuerdo al juego de la oferta y la demanda. Esa situación es objeto de críticas e imputaciones por el gobierno venezolano como causal del problema. En conclusión se está de acuerdo con la hipótesis de la asimetría complementaria de los estados colindantes de acceso al mercado, se considera que desde el gobierno venezolano priva el matiz político sobre la economía y que existe un caos organizado en el tratamiento del diferencial cambiario donde se están beneficiando los diferentes actores aunque se quiera expresar lo contrario. 


\section{REFERENCIAS}

1. ANALDEX - Asociación Nacional de Exportadores de Colombia (2015).

2. ÁLVAREZ, V. (2013). Venezuela: pro y contra de la devaluación. Blog. Recuperado: http://victoralvarezrodriguez.blogspot.com.es/2013/02/ pro-y-contra-de-la-devaluacion.html

3. BECERRA, C. (2016). Lo que debes saber sobre la Memoria y Cuenta 2015 de Nicolás Maduro. En: El Nacional.com Recuperado: http://www. el-nacional.com/politica/Memoria-Cuenta-Puntos-presentacion-Maduro_0_775722564.html

4. CAZAR, E. (2001). El mercado internacional de divisas. Principios Básicos. Ediciones Abya-Yala. 1ª Ed. Quito. Ecuador.

5. CARRIÓN, F. (2011). Economía de Frontera: una atracción fatal. En: Mecanismos de contrabando y tráfico en la triple frontera. (2011). Fronteras. Flacso Sede Ecuador.Programa de Estudios de la Ciudad. Recuperado: https://www.academia.edu/7256014/Mecanismos_de_contrabando_y_ trafico_en_la_triple_frontera.

6. DE SANTIS. J. (2013). Veranito cambiario para los extranjeros que hacen las compras en la frontera (16 de mayo de 2013). En: La Nacion.com.ar. Recuperado:http://www.lanacion.com.ar/1582308-veranito-cambiario-para-los-extranjeros-que-hacen-las-compras-en-la-frontera-argentina.

7. FERNÁNDEZ, C. (2015). Los venezolanos cambian su salario mínimo en Cúcuta por $\$ 56.000$ (Marzo 16, 2015). En: La República.com. Recuperado: http://www.larepublica.co/los-venezolanos-cambian-su-salario-m\%C3\%ADnimo-en-c\%C3\%BAcuta-por-56000_231831.

8. GARCÍA, J. (2010). Los retos, dificultades y amenazas que ha enfrentado la libertad económica en América Latina. En: Revista Ciencias Estratégicas. Vol. 18. No. 23. Ene.-Jun. 2010, pp. 27- 41. Medellín, Colombia. Recuperado: www.redalyc.org/articulo.oa?id=151313724003.

9. HERNÁNDEZ, R. (2014). La economía se desangra por la frontera. Ultimas Noticias. Recuperado: http://www.ultimasnoticias.com.ve/noticias/ actualidad/economia/infografia--la-economia-se-desangra-por-la-fronter.aspx\#ixzz3VIH1HI0O.

10. INVESTING (2015). COP/VEF - Peso Colombiano Bolívar Venezolano. Gráficos Streaming. Recuperado: http://es.investing.com/currencies/copvef-chart.

11. LÓPEZ. A. (2011). La política fiscal de los gobiernos populistas latinoamericanos. Entre la intencionalidad política y la viabilidad económica. Working Papers - CEP Rs 6(2011. Centro de Estudios Políticos y Constitucionales, Spain. Recuperado de www.cep-gob.es/docs/working paper_6PDF?SFVrsn=4.

12. LOZANO, D. (30 de octubre de 2014). Frontera caliente: entre Venezuela y Colombia, paraíso del contrabando. En: lanacion.com.ar. Recuperado: http://www.lanacion.com.ar/1739791-frontera-caliente-entre-venezuela-y-colombia-paraiso-del-contrabando.

13. MARTínEZ, A. (2008). Colombia y Venezuela: desempeño económico, tipo de cambio y relaciones estado-empresarios. Revista de Economía Institucional, vol. 10, № 19, segundo semestre/2008, pp. 265-291. Recuperado: www.economiainstitucional.com/pdf/no19/amartinez19.pdf

14. MARTÍNEZ,H. (2012). La economía subterránea e ilegal en Colombia. Recuperado: http://www.planetapaz.org/index.php/biblioteca6/nuestraspublicaciones/doc_details/186-la-economia-subterranea-e-ilegal-en-colombia?tmpl=component.

15. MARTínEZ, J. (2001). Comercio internacional y globalización. En: La Economía de Mercado, virtudes e inconvenientes Recuperado: http://www. eumed.net/cursecon/15/index.htm

16. MAZAZAVALA, D. La devaluación en el proceso de la crisis venezolana. Recuperado de www.ance.msinfo.info/bases/biblo/texto/NE/NE.31.02.pdf.

17. MENDOZA, J. (2014). El Derrumbe del Modelo Económico en puertas. El inicio de un nuevo ciclo (29/05/2014. Recuperado: https://app.box.com/ shared/58ea5d67bb95dfb66343/1/236856663/27761703296/1.

18. PRODAVINCI. 60 economistas se pronuncian sobre la crisis económica en Venezuela (22 de enero, 2015). En: Prodavinci.com. Recuperado de http://prodavinci.com/2015/01/22/actualidad/60-economistas-se-pronuncian-sobre-la-crisis-economica-en-venezuela-monitorprodavinci/

19. RAMÍREZ, J. (2011). Colombia y Venezuela: dos orillas opuestas de la aldea global en la era post-caída del muro de Berlín. Revista Lebret. №. 3 , diciembre de 2011. Recuperado de www.econpapers.repec.org/RePEc:col:000385:010308. 
20. RAMÍREZ, J.; MANZANO, D.;ZAMBRANO, M. y NOVA, E. (2013). ¿Por qué no le va"tan bien"a la economía de Norte de Santander? Documentos de Trabajo sobre Economía Regional y de Frontera. Núm. 1. Abril 2013. Universidad de Pamplona. Colombia. Recuperado de http://www.unipamplona. edu.co/unipamplona/portallG/home_72/recursos/01_general/22082014/documento_trabaj01.pdf.

21. RESISTENCIA (2014). Por la devaluación del Peso los bolivianos cruzan a comprar (7 de octubre). Recuperado: http://resistenciahuemul.com.ar/ notas/4/33172/por-la-devaluacion-del-peso-los-bolivianos-cruzan-a-comprar-.htm.

22. RODRÍGUEZ, D. (2014). Transmisión del efecto cambiario a la economía de la frontera colombo-venezolana. Ensayos Sobre Economía Regional. Núm. 59. Noviembre, 2014. Recuperado de www.banrep.gov.co/es/eser_59.

23. SAMANIEG0, P. (2011). La economía de la frontera norte del Ecuador. En: Fronteras. Flacso Sede de Ecuador. Programa de Estudios de la Ciudad. Páginas (6-9). Recuperado: https://www.academia.edu/7256014/Mecanismos_de_contrabando_y_trafico_en_la_triple_frontera.

24. SÁNCHEZ, A. (2014). Crisis en la frontera. Documentos de Trabajo sobre Economía Regional. Núm. 197. Enero, 2014. Banco de la República.

25. SELA (2011). Las asimetrías en los procesos de integración de América Latina y el Caribe. Recuperado: http://www.sela.org/media/265454/ t023600005162-0-di_12_cepal_nahuel_oddone.pdf.

26. SELA (2013). Cooperación Regional en elámbito de la Integración Fronteriza. Recuperado de http://www.sela.org/media/265454/t0236000051620-di_12_cepal_nahuel_oddone.pdf.

27. SCHNEIDER, F. y ENSTE, D. (2002). Ocultándose en las sombras. El crecimiento de la economía subterránea. Fondo Monetario Internacional. Recuperado: https://www.imf.org/external/pubs/ft/issues/issues30/esl/issue30s.pdf.

28. STEIMBERG, F. (2004) La nueva teoría del comercio internacional y la política comercial estratégica. Recuperado de www.eumed.net/cursecon/ libreria/

29. Venezuela: el socialismo del siglo XXI y la enfermedad holandesa como estrategia económica (Febrero 19, 2015). Recuperado: http://www. petroleoamerica.com/2015/02/venezuela-el-socialismo-del-siglo-XXI-y.html 